\title{
Chronic respiratory diseases at primary health care level in Georgia: the results of the pilot study
}

\author{
I. Chkhaidze1, T. Maglakelidze², N. Khaltaev³
}

ABSTRACT: Chronic respiratory diseases at primary health care level in Georgia: the results of the pilot study. I. Chkhaidze, T. Maglakelidze, N. Khaltaev.

Background and aim. Millions of people suffer from chronic respiratory diseases (CRD). To address this serious global health problem WHO formed the Global AIliance against Chronic Respiratory Diseases (GARD). Chronic obstructive pulmonary disease (COPD) is a major priority of GARD due to high chronic morbidity and mortality; however, there is still little prevalence data available. The prevalence of COPD in Georgia, as well as other CRD, is suspected to be high.

Methods. GARD Pilot Survey (GAPS) in Georgia had been carried out by the Georgian Respiratory Association. The survey was conducted in the Sagarejo and Mtskheta districts with total population of about 70.000 . All subjects provided information on asthma, bronchitis, respiratory symptoms, smoking, allergic conditions, CRD comorbidi- ty and lifestyle via an interviewer-administered questionnaire. A total of 3,646 questionnaires were analysed.

Results. It was discovered that official data concerning allergic rhinitis, TB and asthma are almost equal, but readings in relation to $\mathrm{CRD}$ are about five times lower according to official data of the Ministry of Health of Georgia. The data results: for allergic rhinitis - 218 in GAPS vs. 177 in the official statistics (for $\mathbf{1 0 0 . 0 0 0}$ population); for TB -105 in GAPS vs. 147 in the official statistics; for asthma -250 in GAPS vs. 374 in the official statistics; the data about CRD according to our survey is almost five times higher - 365 in GAPS vs. 84 in the official statistics (for 100.000 population).

Conclusions. It is necessary to expand the survey to the entire country population. Country results are likely to be useful and interesting for local doctors and managers, as well as for officials.

Monaldi Arch Chest Dis 2009; 71: 4, 141-146.

Keywords: Chronic respiratory diseases, COPD, GARD.

I Tbilisi State Medical University, Tbilisi, Georgia.

2 Georgian Respiratory Association: Medical-diagnostic centre of the Tbilisi State University, Tbilisi, Georgia.

3 Allergic Rhinitis and Its Impact on Asthma (ARIA): World Health Organization, Geneva, Switzerland.

Correspondence: Ivane Chkhaidze, Tbilisi State Medical University: 33, Vazha Pshavela Av, 0177, Tbilisi, Georgia; e-mail: ivane ch@internet.ge

\section{Introduction}

Hundreds of millions of people in the world suffer from chronic respiratory diseases (CRD), including 300 million people with asthma, 210 million people with chronic obstructive pulmonary disease (COPD), 400 million with allergic rhinitis and many millions with other chronic respiratory diseases. To address this serious and growing global health problem the Global Alliance against Chronic Respiratory Diseases (GARD) was formed following a mandate from the World Health Assembly [1]. The Georgian Respiratory Association (GRA) representing all major respiratory societies of the country joined GARD in 2006.

COPD as a major priority issue of GARD due to high chronic morbidity and mortality is the only major chronic disease that is continuing to increase in both prevalence and mortality [2]. However, there is still little prevalence data available [3-8]. Before the establishment of the Global Initiative for Chronic Obstructive Lung Disease (GOLD) guidelines, international standards for the diagnosis and definition of COPD were lacking and the diagnostic criteria complex, making geographic comparison difficult.

The prevalence of COPD in Georgia is suspected to be high due to high smoking rate and air pollution. However, the term "COPD" is almost unknown to the general population, and for many doctors COPD diagnostic criteria are still not broadly used. COPD, prevalence data for Georgia based on official statistic is quite low $(0.47 \%$ for chronic bronchitis).

The situation concerning asthma prevalence is better, as Georgia took part in ISAAC study $[9,10]$, although the results only related to the pediatric population.

There is no official data on allergic rhinitis (AR) which is one of the most prevalent respiratory diseases with a serious burden to society and heavily impacting on quality of life. For instance the indirect cost per employee with AR per year due to loss of productivity is $\$ 593$, respiratory infections $\$ 181$, diabetes $\$ 95$ and coronary heart disease $\$ 40[11]$. 
No official statistics have been provided by the Ministry of Health of Georgia in relation to other $\mathrm{CRD}$, because not every chronic diseases of respiratory system is included in the list of State medical standards.

Therefore, achieving signed agreement between WHO/GARD and Georgian Respiratory Association in July 2006 was a great challenge not only for GRA, but for the whole country as well.

It was decided that a pilot survey should be conducted in two districts of the country and depending on the results, expand the study to the other regions of Georgia as well.

In this study we have focused our CRD survey on the primary health care (PHC) using a two step approach:

- Step 1: collect questionnaire-based information on respiratory symptoms, tobacco use, indoor and outdoor pollution in PHC.

- Step 2: use standardised physical measurements to confirm diagnosis in selected patients with COPD.

\section{Methods}

GARD Pilot Survey (GAPS) in Georgia was carried out by the Georgian Respiratory Association from February 2007 to April 2007. The survey was based on methodology proposed by Maesano and Khaltaev [12].

Two districts: Sagarejo and Mtskheta were chosen to assess the prevalence of chronic respiratory diseases. Sagarejo and Mtskheta districts are situated about 30 kilometres from the Georgian capital to the west and east respectively. The districts health care system consists of 2 hospitals and about 50 outpatient clinics. The population of Sagarejo district is 60,000 , among them $30,000 \mathrm{fe}$ male and 30,000 male. The population of Mtskheta district is 65,000 , among them 34,000 female and 31,000 male [13]. The survey was conducted in parts of these two districts with total population about 70,000 .

3,822 patients visiting outpatient clinics were screened and the data has been analysed (figure 1).

At the first phase of GAPS the respiratory diseases in individuals from 5 years of age had been investigated. Anyone attending the afore-mentioned facilities for any reason was included in survey. In Sagarejo survey were conducted in February and March, in Mtskheta - in April.
PHC level was chosen for rapid evaluation of CRD patients flow and plan health professionals' workload, assess the need of specialists, equipments and drugs and initiate a comprehensive training and workforce development programmes.

The survey consisted of a questionnaire administered by a physician (it should be noted that in Georgia historically only physicians take part in the patients' evaluation, examination, etc). All subjects provided information on asthma, bronchitis, respiratory symptoms, smoking, allergic conditions, CRD co-morbidity, lifestyle and environment via an interviewer-administered questionnaire. The main part of questionnaire was about different respiratory disorders, such as asthma, tuberculosis, COPD, pneumonia, allergy.

Asthma was considered if a subject replied affirmatively to the question "has a doctor ever told you that you have asthma?" or if patient in the previous 12 months had suffered from an asthma attack or currently used asthma medication (shortacting $\beta$-agonist, inhaled corticosteroids, etc).

Tuberculosis was considered if a subject replied positively to the question "has a doctor ever told you that you have tuberculosis?".

CRD were considered if a subject replied positively to the questions "Do you usually cough most days for 3 consecutive months or more during the year?" and "Do you bring up phlegm most days for 3 consecutive months or more during the year?" CRD prevalence was calculated based on symptoms of cough, sputum production, dyspnea, and/or a history of exposure to risk factors for the disease [14].

In a group of CRD patients (92 patients) with more than three years history of undiagnosed chronic cough a spirometry has been performed to confirm diagnosis of COPD. Spirometry was performed according to procedures recommended by ERS/ATS using spirometry [15]. Spirometers (Flowscreen Pro, Jaeger) were calibrated in the beginning of each workday. After the initial procedure, $2.5 \mathrm{mg}$ salbuta$\mathrm{mol} /$ albuterol was administered via nebulaizer mask over 5 to 10 minutes to all subjects. After 15 minutes post bronchodilatator spirometry was performed. All spirometry loops were reviewed by two high qualified investigators. The results were confirmed by the chief pulmonologists.

After data analysis the patients were placed into one of four diagnostic categories according to

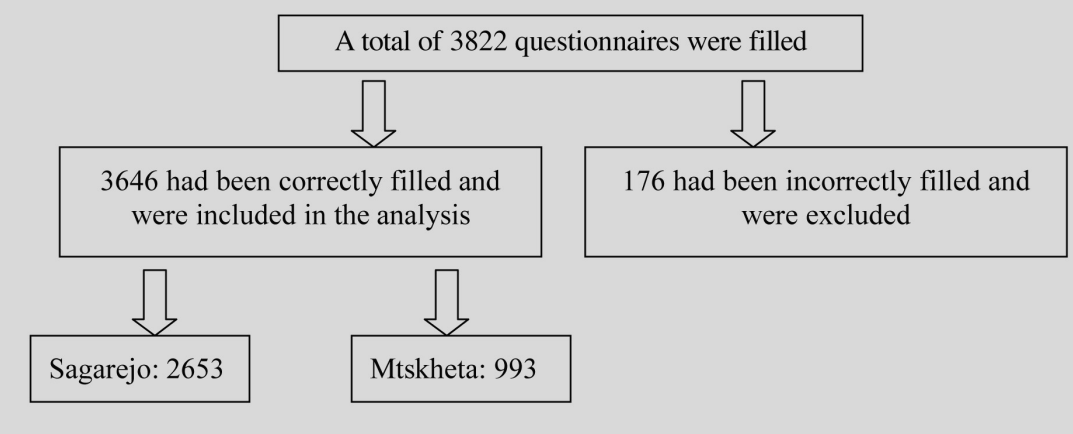

Fig. 1. - Selection of the study population for the GAPS study. 
GOLD criteria. All study diagnoses were based on post-bronchodilatator spirometry values.

Staging was defined according to the GOLD guidelines as follows [14]:

- stage I (mild COPD): $\mathrm{FEV}_{1} / \mathrm{FVC} \leq 70 \%$ and $\mathrm{FEV}_{1} \geq 80 \%$ predicted;

- stage II (moderate COPD): $\mathrm{FEV}_{1} / \mathrm{FVC} \leq 70 \%$ and $\mathrm{FEV}_{1} 50-80 \%$ predicted;

- stage III (severe COPD): $\mathrm{FEV}_{1} / \mathrm{FVC} \leq 70 \%$ and $\mathrm{FEV}_{1} 30-50 \%$ predicted;

- stage IV (very severe COPD): $\mathrm{FEV}_{1} / \mathrm{FVC}$ $\leq 70 \%$ and $\mathrm{FEV}_{1}<30 \%$ predicted.

Allergy was considered if a subject replied positively to the questions "Are you allergic to anything?"

Allergic rhinitis was considered if a subject replied positively to the questions "In the past 12 months, have you had a problem, apart from when suffering from cold or flu, with sneezing, runny nose or blocked nose" and/or "In the past 12 months, has this nose problem been accompanied by itchy-watery eyes?

Subjects were classified according to smoking habits as current smokers, past smokers, and nonsmokers. They were considered smokers (current or past) if they stated in the questionnaire that they had smoked at least 20 packs of cigarettes in a lifetime, or at least one cigarette per day for 1 year.
Current smokers were those who reported currently smoking and were divided into two subgroups according to the pack years smoked in a lifetime (light smokers, 15 pack years; moderate to heavy smokers $>15$ pack years). Subjects were considered past smokers if they had been smokers (as defined above) and had stopped smoking at least 1 month previously. All the other subjects were considered as non-smokers.

The other risk factors considered in the analysis were self reported serious respiratory infections (pneumonia) before the age of 5 years.

Occupational exposures were defined as exposure to biological dusts, mineral dusts, gases or fumes and classified as none or high exposure.

Statistical analysis. A total of 3,646 subjects, who answered the questions on chronic respiratory symptoms during the clinical interview were analysed. Comparisons between variables were tested by Student $t$ test. The statistical analysis was performed using specially created software.

\section{Results}

Table 1 presents the characteristics of the study population. Percentages for Sagarejo and Mtskheta

Table 1. - Characteristics of participants in the GAPS study

\begin{tabular}{|c|c|c|c|}
\hline Individual variables & Total & Sagarejo & Mtskheta \\
\hline Subjects & 3646 & 2653 & 993 \\
\hline \multicolumn{4}{|l|}{ Sex } \\
\hline Male & $1487(40.9)$ & $1051(39.6)$ & $436(43.9)$ \\
\hline Female & $2159(59.1)$ & $1602(60.4)$ & $557(56.1)$ \\
\hline \multicolumn{4}{|l|}{ Age yrs } \\
\hline $5-14$ & $536(14.7)$ & $396(10.9)$ & $140(3.8)$ \\
\hline$>14$ & $3110(85.3)$ & $2257(61.9)$ & $853(23.4)$ \\
\hline \multicolumn{4}{|l|}{ Smoking status } \\
\hline Never-smoker & $2910(79.9)$ & $2126(80.2)$ & $784(78.9)$ \\
\hline Current and past smoker & $736(20.1)$ & $527(19.8)$ & $209(21.1)$ \\
\hline Respiratory infections (pneumonia ever) & $1269(34.8)$ & $1071(40.4)$ & $198(19.9)$ \\
\hline Allergy & $436(11.9)$ & $342(12.9)$ & $94(9.5)$ \\
\hline Cough & $729(19.9)$ & 477 (17.9) & $252(25.4)$ \\
\hline Phlegm & $511(14.0)$ & $338(12.7)$ & $173(17.4)$ \\
\hline CRD & $256(7.0)$ & $195(7.4)$ & $61(6.1)$ \\
\hline Asthma & $175(4.8)$ & $115(4.3)$ & $60(6.0)$ \\
\hline Allergic rhinitis & $153(4.2)$ & $116(4.4)$ & $37(3.7)$ \\
\hline TB & $74(2.0)$ & $36(1.3)$ & $38(3.8)$ \\
\hline \multicolumn{4}{|l|}{ Educational level } \\
\hline High & $730(20.0)$ & & \\
\hline Medium (secondary school) & $1990(54.6)$ & & \\
\hline Low (primary school) & $837(23.0)$ & & \\
\hline No education & $89(2.4)$ & & \\
\hline
\end{tabular}

Data are presented as $\mathrm{n}$ and $\%$. 
districts are shown taking into account number of subjects in each district: 2653 in Sagarejo and 993 in Mtskheta (the survey in Mtskheta was conducted in April, which accounts for why the number of patients is lower).

The overall number of asthma patients was 4.8\% - 175 cases. Among them 115 cases were $(4.3 \%)$ in Sagarejo and 60 cases $(6.0 \%)$ in Mtskheta. In the entire study group the number of asthmatics was higher in females than in males (3.2\% versus $1.6 \%)$. It is very important to add that in 32 cases ( $18.2 \%$ in the whole asthma patients) asthma was diagnosed during the survey. These patients either did not refer to medical facilities earlier or had an undiagnosed episodes of chronic cough or/and wheezing.

The number of patients with cough was $19.9 \%$ (729 cases), among them 477 cases (17.9\%) in Sagarejo and 252 cases $(25.4 \%)$ in Mtskheta. In the whole study group the number of coughing patients was higher in males than in females $(11.8 \%$ versus $8.2 \%$ ).

The number of CRD patients diagnosed by questionnaire was $7 \%$ (256 cases), among them 195 cases (7.4\%) in Sagarejo and 61 cases (6.1\%) in Mtskheta. In the whole study group the CRD number was higher in males than in females $(8.3 \%$ versus $4.6 \%$ ).

In 92 patients with more than a three year history of CRD a spirometry has been performed to confirm diagnosis of COPD. A diagnosis of COPD was established in 62 patients $(67.4 \%)$ out of 92 . Among them 36 were men, 26 women. There were three subjects $(4.8 \%)$ younger than 45 years among patient with COPD: 35 years old women with stage II, 41 years old man with stage III and 43 years old man with stage I.

All of others were older than 45 year; the age of oldest subject was 72 years old.

Most of the subjects (25 patients, $40.3 \%$ ) had moderate disease (stage II). Among the subjects with COPD, 32.2\% (20 subjects, 14 men, 22.5\%; 6 women, 9.6\%) had an $\mathrm{FEV}_{1}$ less than $50 \%$ predicted (stage III). The stage I of COPD $\left(\mathrm{FEV}_{1}\right.$ $>80 \%$ predicted) were stated in 17 subjects $(27.4 \%)$, among them 10 women $(16.1 \%)$. No cases of very severe COPD (stage IV) were diagnosed.

So, in general, there were 17 patients with COPD stage I, 25 patients with COPD stage II and 20 patients COPD stage III.

The diagnosis of COPD was higher among smokers than nonsmokers. The frequency of severe disease was substantially higher among cur- rent and former smokers compared with nonsmokers. Ninety-two percent of those men with severe COPD were current or former smokers. Only one man among those with stage III COPD was a non-smoker. In the whole group of subjects with COPD there were only 3 nonsmoking men, so the total percentage of smokers among men with COPD was 91.6.

Allergy was diagnosed in $11.9 \%$ (436 cases), among them 342 cases (12.9\%) in Sagarejo and 94 cases $(9.5 \%)$ in Mtskheta. In the whole study group number of allergic patients was higher in females than in males $(8.2 \%$ versus $3.8 \%)$.

Allergic rhinitis was diagnosed in $4.2 \%$ (153 cases), among them 116 cases (3.2\%) in Sagarejo and 37 cases $(1.0 \%)$ in Mtskheta. In the whole study group allergic rhinitis was higher in females than in males $(3.0 \%$ versus $1.2 \%)$.

The number of TB cases was $2.0 \%$ (74 cases), among them 36 cases $(0.99 \%)$ in Sagarejo and 38 cases $(1.04 \%)$ in Mtskheta. In the whole study group TB in males was more than two times higher than in females $(3.0 \%$ versus $1.2 \%)$.

The number of smokers (past and present) was $20.1 \%$ (736 cases), among them 527 cases (19.8\%) in Sagarejo and 209 cases $(21.1 \%)$ in Mtskheta. There were 712 male $(19.63 \%)$ and 24 female smokers $(0.66 \%)$. But in adult males the percentage of smokers was $(58.12 \%)$.

The co-existence of chronic cardiovascular diseases (CVD) and respiratory disease was studied and separate analyses of CVD had been performed (table 2). The total number of patients with chronic CVD was 891, with higher level in female patients ( $16.4 \%$ female vs. $8.1 \%$ male). The number of patients with both diseases: CVD and CRD were 261. But in this group the sex ratio was almost similar $(3.57 \%$ in females and $3.60 \%$ in males).

It is difficult to compare GAPS finding to the official data, because: (a) Ministry of Labour, Health and Social Affairs (MoLHSA) of Georgia did not provide statistics for the same diseases as in our survey and (b) duration of survey in Sagarejo and Mtskheta was too short and focused on PHC patients. Figure 2 shows the comparison between GAPS and official data (MoLHSA data are based on primary care records) for the prevalence of four diseases: allergic rhinitis, TB, asthma and COPD (defined from the MoLHSA Statistical Book "Other obstructive diseases of the lung"). If the data concerning the prevalence of allergic rhinitis, TB and asthma are comparable: for allergic rhinitis - 218 in GAPS vs. 177.4 in the official statistics

Table 2. - Distribution of patients with cardiovascular diseases

\begin{tabular}{lcccccc}
\hline Patients & \multicolumn{2}{c}{ Sagarejo } & \multicolumn{2}{c}{ Mtskheta } & \multicolumn{2}{c}{ Total } \\
\cline { 2 - 7 } & Female & Male & Female & Male & Female & Male \\
\hline Patients with CVD & $468(12.9 \%)$ & $218(6.0 \%)$ & $128(3.5 \%)$ & $77(2.1 \%)$ & $596(16.4 \%)$ & $295(8.1 \%)$ \\
\hline Patients with CVD and CRD & $90(2.5 \%)$ & $87(2.5 \%)$ & $40(1.1 \%)$ & $44(1.2 \%)$ & $130(3.57 \%)$ & $131(3.60 \%)$ \\
\hline
\end{tabular}




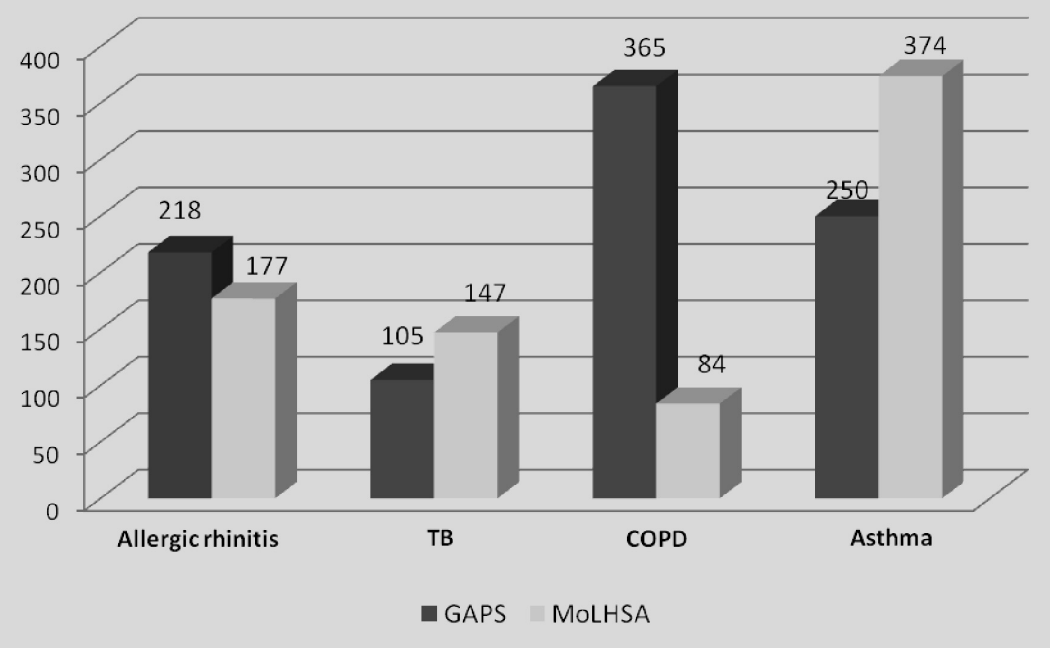

Fig. 2. - Comparison between GAPS and MoLHSA data for the prevalence of the selected diseases (for 100.000 population).

(for 100.000 population); for TB -105 in GAPS vs. 147 in the official statistics (for 100.000 population); for asthma -250 in GAPS vs. 374.8 in the official statistics (for 100.000 population); The readings relating to CRD/COPD according to our survey are almost five times higher - 365 in GAPS vs. 83.6 in the official statistics (for 100.000 population).

\section{Discussion}

The results of our analysis show that: (1) a considerable percentage of subjects younger than 45 year already suffered from CRD; $(2)$ in the majority of subjects with spirometry confirmed COPD the severity of the disease was moderate; (3) Due to high prevalence of CRD at PHC we can assume that the real prevalence of COPD in Georgia is higher, than the official data.

Our results suggest that substantial number of population over 45 have undiagnosed chronic lower airway obstruction. Moreover, the majority of these patients have moderate to severe stage of COPD.

Why is COPD diagnosis so often missed and why is the country's official data so different with the survey data? The main reason is that according to our survey, many physicians are not fully aware of symptoms of COPD.

This is usually due to the lack of devices usage; often that they did not use spirometry to define or confirm diagnosis. There are major gaps in the knowledge of the basics of COPD diagnostic and management guidelines.

Secondly, there is no exactly "COPD" diagnosis in the Georgian state medical standards list. A similar definition is "Other obstructive diseases of the lung". Doctors are forced to use other diagnosis as well; such are "Chronic and unspecified bronchitis" or "Emphysema". Fortunately, since 2006 MoLHSA moved from the State medical standards towards to medical guidelines and soon all doctors will use in their everyday practice COPD up-to-date guidelines.
Thirdly, patients often used to seek medical advice in the late stages of disease, when COPD symptoms affect their quality of life [16, 17]. In many cases patients even do not approach a doctor for diagnosis until they are hospitalized for an acute exacerbation of COPD.

Our results support evidence that the disease develops earlier than is usually believed [18, 19]. This should be taken into account when planning future widespread programmes for early detection of the disease and preventive measures.

Women had a lower prevalence of both chronic symptoms (cough, bronchitis) and COPD than men, in agreement with the findings of previous studies [20, 21]. While the sex difference in chronic symptoms was entirely explained by the different distribution in exposure to the considered risk factors (as shown in the multivariate analysis), the significantly higher risk of having COPD for men may be due either to the fact that they were more exposed to other hazards (occupational, lifestyle, etc) or to their greater susceptibility than women [19].

In conclusion, COPD is an important health problem even in young adults, both because of the high prevalence of the disease and the frequent use of healthcare resources. It is necessary to expand the survey in whole country population. It is necessary to use more broadly spirometry in the further surveys to confirm all COPD cases. It is also necessary to conduct training process in the medical facilities to study main features of CRD and COPD. Country results might be useful and interesting for local doctors and managers, as well as for Ministry of Health of Georgia and other officials.

\section{References}

1. Global Alliance Against Chronic Respiratory Diseases (GARD). General Meeting Report Beijing, People's Republic of China, 28-29 March 2006. WHO, 2006.

2. Bousquet J, Khaltaev N. Global surveillance, prevention and control of chronic respiratory diseases: a comprehensive approach. Geneva, World Health Organization, 2007: 146. 
3. Halbert RJ, Sisonaka S, George D, Iqbal A. Interpreting COPD prevalence estimates: what is the true burden of disease? Chest 2003; 123: 1684-1692.

4. Mannino DM, Gagnon RC, Petty TL, Lydick E. Obstructive lung disease and low lung function in adults in the United States: data from the National Health and Nutrition Examination Survey, 1988-1994. Arch Intern Med 2000; 160: 1683-1689.

5. Pen a VS, Miravitlles M, Gabriel R, et al. Geographic variations in prevalence and underdiagnosis of COPD: results of the IBERPOC multicenter epidemiological study. Chest 2000; 118: 981-989.

6. Viegi G, Pedreschi M, Pistelli F, et al. Prevalence of airways obstruction in a general population: European Respiratory Society versus American Thoracic Society definition. Chest 2000; 117: 339S-345S.

7. Dickinson JA, Meaker M, Searle M, Ratcliffe G. Screening older patients for obstructive airways disease in a semi-rural practice. Thorax 1999; 54: 501-505.

8. von Hertzen L, Reunanen A, Impivaara O, Malkia E, Aromaa A. Airway obstruction in relation to symptoms in chronic respiratory disease: a nationally representative population study. Respir Med 2000; 94: 356-363.

9. The International Study of Asthma and Allergies in Childhood (ISAAC) Steering Committee. Worldwide variations in the prevalence of asthma symptoms: the International Study of Asthma and Allergies in Childhood (ISAAC). Eur Respir J 1998; 12: 315-335.

10. Weiland SK, Björkstén B, Brunekreef B, Cookson W, von Mutius E, Strachan DP, and the International Study of Asthma and Allergies in Childhood Phase II Study Group. Phase II of the International Study of Asthma and Allergies in Childhood (ISAAC II): rationale and methods. Eur Respir J 2004; 24: 406-412.
11. Lamb CE, Ratner PH, Johnson CE, et al. Economic impact of workplace productivity losses due to allergic rhinitis compared with select medical conditions in the United States from an employer perspective. Curr Med Res Opin 2006; 22: 1203-10.

12. Martins P, Pinto JR, do Céu Teixeira M, et al. Underreport and underdiagnosis of chronic respiratory diseases in an African country. Allergy 2009 Feb 6.

13. Demographic Yearbook of Georgia. UNFPA, Tbilisi, 2004.

14. http://www.goldcopd.com

15. Miller MR, Hankinson J, Brusasco V, et al. Standardisation of spirometry. Eur Respir J 2005; 26: 319-338.

16. Van den Boom G, Rutten-van Molken MP. Association between health related quality of life and consultation for respiratory symptoms: results from the DIMCA programm. Eur Respir J 1998; 11: 67-72.

17. Tinkelman DG, Price DB, Nordyke RJ, Halbert RJ. COPD screening efforts in primary care; what is yield? Prim Care Respir J 2007; 16: 41-48.

18. Cerveri I, Accordini S, Corsico A, et al for ISAYA Study Group. Chronic cough and phlegm in young adults. Eur Respir J 2003; 22: 413-7.

19. de Marco R, Accordini S, Cerveri I, et al for the European Community Respiratory Health Survey (ECRHS) Study Group. An international survey of chronic obstructive pulmonary disease in young adults according to GOLD stages. Thorax 2004; 59; 120-125.

20. Eagan TML, Bakke PS, Eide GE, Gulsvik A. Incidence of asthma and respiratory symptoms by sex, age and smoking in a community study. Eur Respir J 2002; 19 : 599-605.

21. Xu X, Weiss ST, Rijcken B, et al. Smoking, changes in smoking habits, and rate of decline in $\mathrm{FEV}_{1}$ : new insight into gender differences. Eur Respir J 1994; 7: 1056-61.

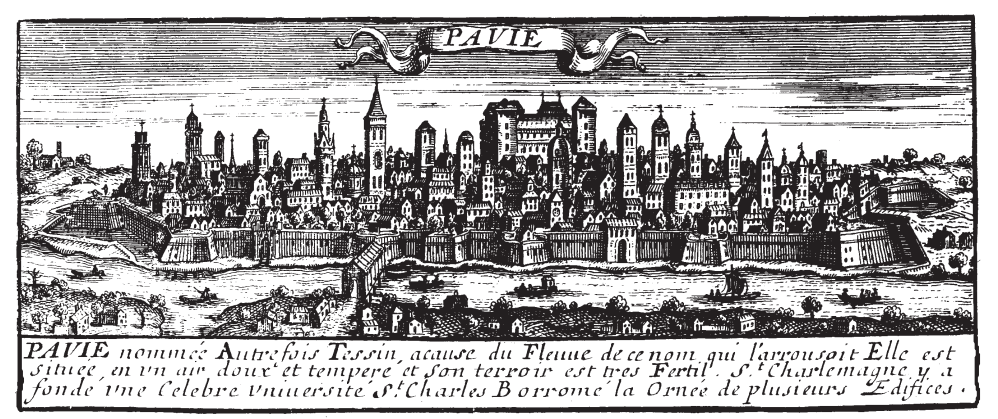

